\title{
V Shanta - Tribute to the Legend and a Saint
}

\author{
K. Harish ${ }^{1}$ - K. S. Gopinath ${ }^{2}$ \\ Published online: 6 March 2021 \\ (C) Indian Association of Surgical Oncology 2021
}

"Successful life is one that makes a positive difference in other people's lives"

Dr. Viswanathan Shanta was a doyen in Oncology having dedicated her life to patient care for over 6 decades. She is known for her outstanding and significant efforts in making quality and affordable cancer treatment available in the country. She was the Chairman \& Executive Chairman of the Cancer Institute, established by Women's India Association (WIA) Chennai, which has been rated by the WHO as the top ranking cancer centre in the country.

\section{Early Life}

Dr. V. Shanta was born to Viswanathan and Balaparvati in a distinguished scientific family of India in Mylapore, Chennai on 11th March 1927. She hails from a family of two Nobel laureates; her immediate grand uncle being Sir C V Raman and her uncle Dr. Subramaniam Chandrashekhar. Her grandfather was a voracious reader and was her constant source of inspiration. She wanted to emulate him and make some unique contribution. She was driven by the need to achieve something in life and to do something different. When she completed schooling at National Girls High School (now P.S. Sivaswamy Iyer Girls Higher Secondary School), she was determined to get into the medical profession. Miss Wheel, her Principal at school, instilled tremendous discipline in her and would speak on honesty, caring nature and so on. This again made a deep impression on her. She completed intermediate in 1943, when she was 17 , and waited a year

K. Harish

drkhari@yahoo.com

1 Department of Surgical Oncology, HCGMSR Cancer Centre, M S Ramaiah Medical College \& Hospital, Bangalore 560054, India

2 HCG Cancer Centre, Bangalore 560027, India
Fig. 1 1927-2021. When the sick approach the gates of the Institute, weak in body and spirit, full of fear, there is only one response; you have to become a part of them

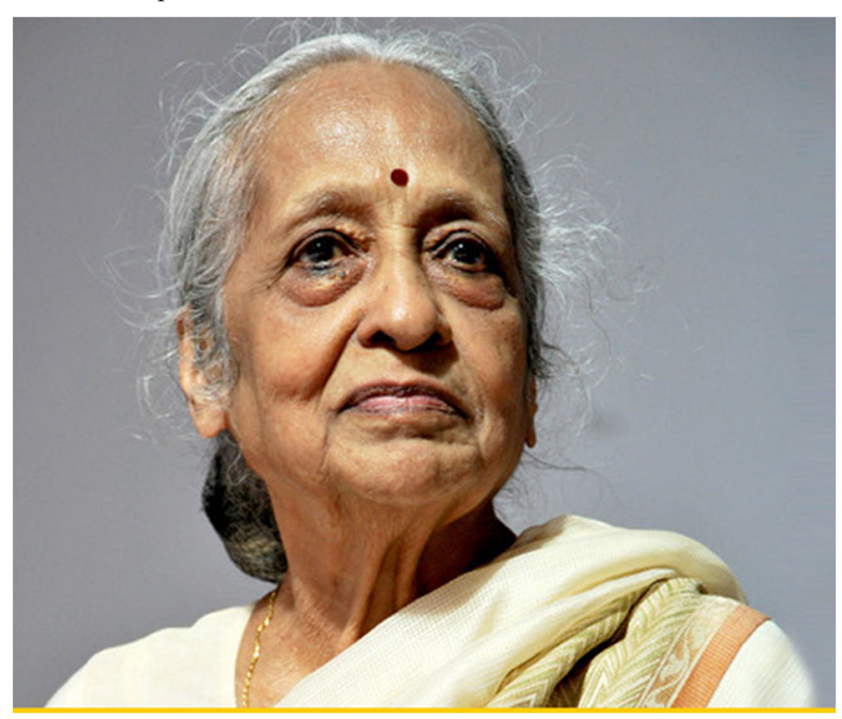

(as she was under-aged) to join medical college - her dream. That year, when she stayed at home, it was an important period as she read a lot of literature, which she could not do after she joined the Madras Medical College in 1944.

\section{Education}

In pre independent India, most girls would not go to school. However, Shanta belonged to an intellectual family where women were educated but rarely took to a career. Many would marry and settle down as homemakers after graduation. Although some would involve in social activities, teaching or nursing, professional career in medicine for a woman was unknown in the family. Shanta wanted to be different. She came across people like Lady Duffrin and Dr. Muthulaxmi 
Fig. 2 Graduation: 1949. She believed she could; she did

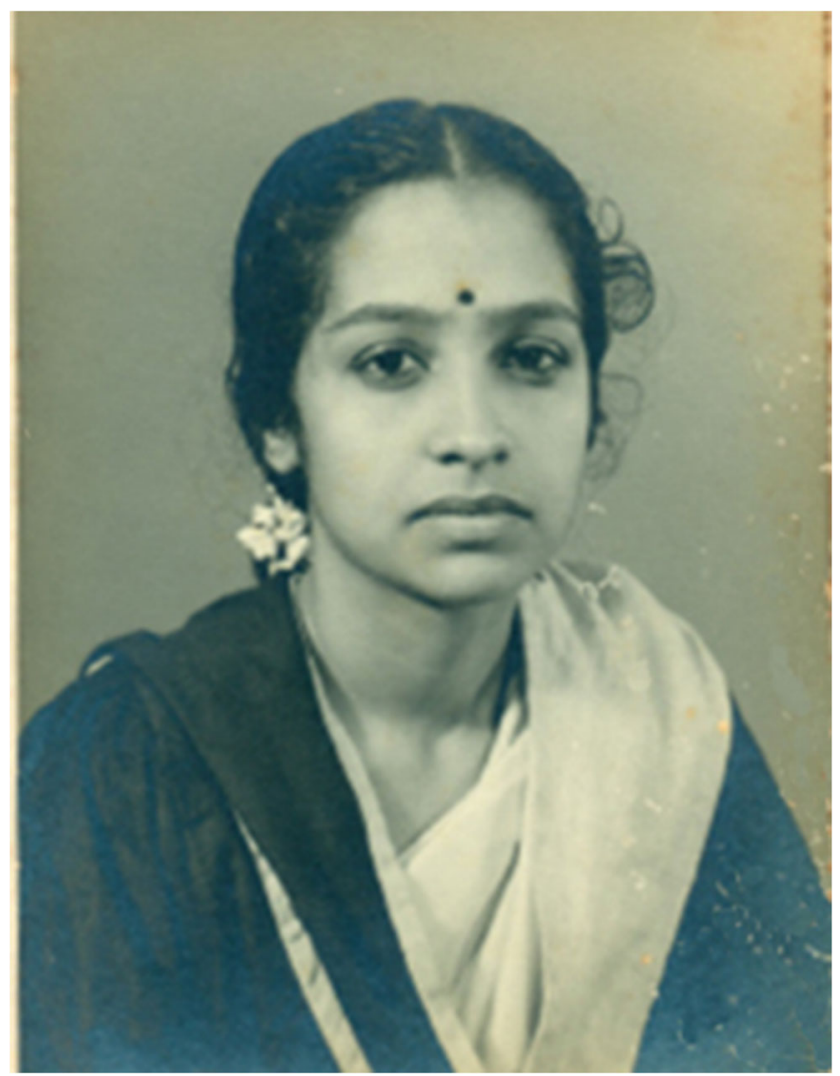

Reddy who made lasting impressions on her resulting in her decision to pursue a career in medicine.

She graduated in 1949 with MBBS; one of ten girls in a class of a hundred. She was fortunate to have had great teachers who, by their codes of discipline, ethics, integrity and knowledge, acted as role models and shaped her thoughts, words and deeds. That was an era when penicillin was just put to clinical use and kept under lock and key! She then completed D.G.O. in 1952 and M.D., in Obstetrics \& Gynecology in 1955. She was later trained in Oncology at Toronto and in bone marrow transplantation in the UK.

\section{The Turning Point}

The dynamics and interconnect between Dr. V Shanta, the Cancer Institute (WIA) where she has had her entire career, Dr. Krishnamurthy and Dr. Muthulaxmi Reddy make them inseparable. She was inspired by Dr. Muthulaxmi Reddy, the first lady medical graduate of India who later established the Cancer Institute on June 18th 1954, (the first comprehensive cancer centre in south India). The biggest turning point in Dr. Shanta's career was her posting in the cancer ward at the
Government Hospital. As destiny would have it, during her posting in internship, she came under direct influence of Dr. S Krishnamurthy an idealist, visionary and a strict disciplinarian, who became her mentor. He had come back from the United States to set up a cancer ward in a Government Hospital. Incidentally, Dr. Krishnamurthy happened be the son of her childhood idol, Dr. Muthulaxmi Reddy.

Although she was appointed by the Government and was posted to the Women and Children Hospital, she decided to spurn the offer and join the Cancer Institute instead in April 1955, much to the dismay of many of her kin. She was also earlier a part of the campaign for the cancer relief fund opened by Dr. Muthulaxmi Reddy prior to setting up of the Cancer Institute. For three years she worked as honorary staff after which, the Institute offered to pay her Rs.200 per month and a place to stay within the campus. She then moved into the campus and remained there ever since. While a lot changed in cancer and its treatment, what remained unchanged, caught in stillness of time was her office and a small dwelling unit within the campus. She led a very simple and humble life till the end with a single passion of how she could do something more to cancer patients.

\section{Career as Clinician, Teacher and Administrator}

\section{"Of all inequalities, inequalities in health care is the most inhuman"}

She played a pioneering role in all the achievements of the Institute. In the initial years, only she and Dr. Krishnamurthy were the doctors and would alternate their duties. She had a hard time, but the excitement of working scientifically in a collaborative spirit of enquiry kept her going. Scrupulous fundamental procedures were put in place from the very beginning. It included a detailed and comprehensive case note and pathologic confirmation of all tumors. Detailed and accurate documentation of case sheets is a hallmark of the Institute even today. She played an important role along with Dr. Krishnamurthy in the development of the Cancer Institute (WIA) from a cottage hospital of 12 beds to a major comprehensive Cancer Centre comprising of 650 beds of national and international stature. Established as a voluntary, charitable, non-profit institution with public donations it has remained true to its words and spirit with added attributes of discipline, honesty, integrity and selfless service.

In 1956, a Cobalt-60 unit Eldorado A was donated by the Atomic Energy Agency to the Cancer Institute. She recalled that day "We started receiving calls where people were suddenly wondering how we, an institute that operated from Sewagram-type huts, got chosen to receive the Cobalt-60 unit 
Fig. 3 Pandit Jawaharlal Nehru (1961): I must say that I have been somewhat bowled over by my visit to the Cancer Institute (WIA). I saw a marble slab that I had laid as a foundation stone nine years ago. The progress since then has been phenomenal, extraordinarily rapid, not in terms of brick and mortar but in quality of work. I wish that the many foundation stones that I have laid in different parts of the country for various purposes showed very nearly the same results as this has done. It is an inspiring example of good work done

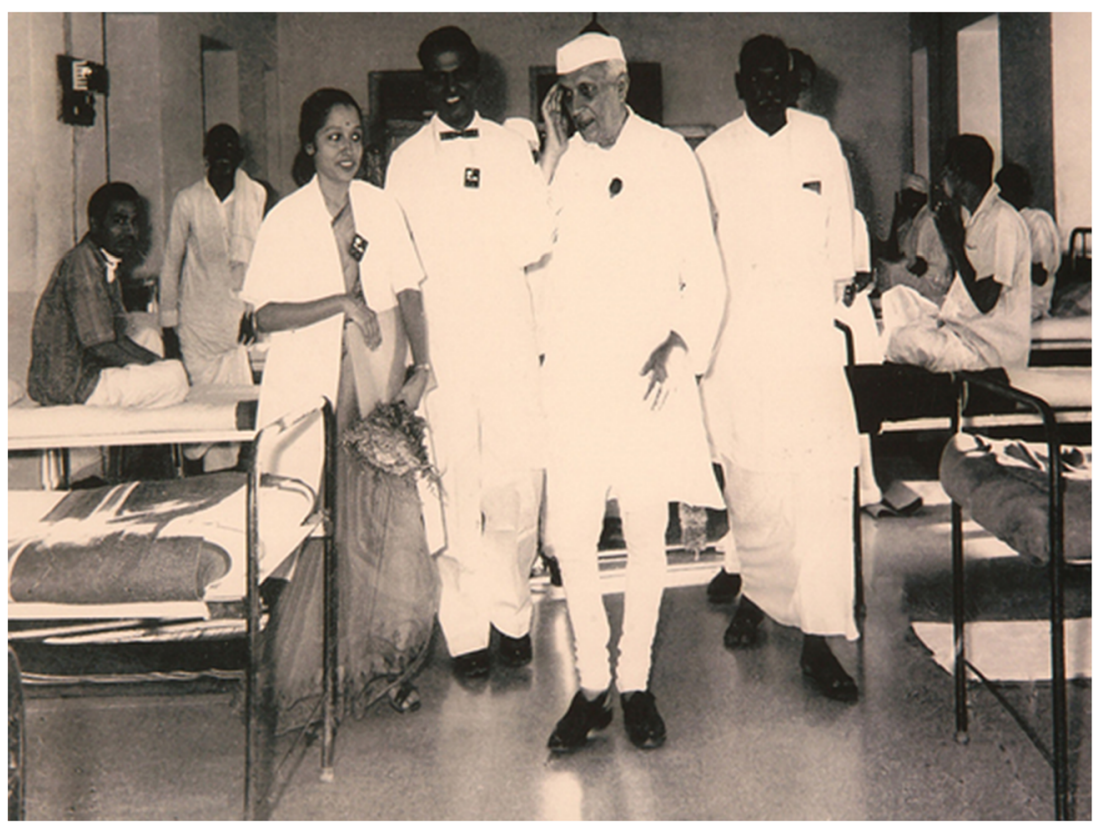

when even the government hospitals didn't have it yet. We woke up one morning to find ourselves famous. It was remarkable!" The institute also established the first nuclear medicine department in oncology the same year. She was instrumental in setting up the first pediatric oncology unit in the country in 1960 . She set up the first medical oncology unit and the required blood component unit in the country in 1971.

She conducted India's first successful trials of combination therapy, leading to a dramatic breakthrough in the control and cure of oral cancer. Simultaneously, Dr. Shanta conducted path breaking research on cervical cancer, breast cancer and pediatric leukemia, publishing the results in international journals and establishing the Institute as India's first Regional Cancer Research and Treatment Center in 1975. She then became the Director from 1980 to 1997 and later Chairperson of the Cancer Institute (WIA). As director from 1980, Shanta strove to make the Institute a world-class research center with institutional partners in Europe, North America, and Japan and state-of-the-art laboratory and imaging equipment. In 2000, she opened India's first hereditary cancer clinic.

She is credited for developing India's first major cancer survey and programme for early detection of cancer in rural areas. She trained hundreds of village nurses to screen rural women for cervical cancer. She received the Nazli-Gad El Mawla Award for cancer control in resource poor country in Brussels in 2002.

She did not think of a life beyond the institution. Service was of primary concern and working for a cause seemed to be the "be-all" and "end-all" for this noble lady who stayed single. Her entire medical life spanning over 6 decades was dedicated to the mission of organizing care of cancer patients, the study of the disease, its prevention and control, the generation of specialists and scientists in different aspects of Oncologic Sciences. In this context, the Institute was the first in India to start DM (Med Oncology) and MCh (Surg Oncology) in 1984; more than 250 of whom now practice throughout the subcontinent. The qualities of discipline, honesty, integrity and service present in the Institute are infectious. The rub off has resulted in one of the protégés being awarded Padma Sri for selfless service in Barak Valley.

Registration of cancer as a disease is mandatory and pivotal for planning cancer control. After much persuasion by the Cancer Institutue (WIA), three ICMR-sponsored demographic registries were established in Bombay, Bangalore and Madras, in 1982. The data from these registries in 1984 provided the basis for the National Cancer Control Project in 1986. Nobody valued data more than her. When people ridiculed that we could never follow-up on patients in India, Dr. Shanta showed the way to assess a cancer patient's survival rate. One of the hallmarks of the institution is the tumor registry that includes a hospital registry and a demographic registry. Both are acclaimed as the best in the country and probably a benchmark. The case sheet documentation, storage and retrieval are probably one of the best. Not a single case file is lost since 1955. In addition, the follow up exceeds $90 \%$ which by itself is a record in the Indian context. This is a place 
worth visiting for the sheer magnitude of the structure and functioning of the registry. The place also hosts the preventive oncology division which creates cancer awareness, public education, and early detection.

Dr. Shanta was the mentor of the massive population-based surveillance study, the Tamil Nadu Cancer Registry Project, which covers the state's population of 80 million people, the largest population covered by any cancer registry in the world. She was awarded the International Association of Cancer Registries Award for work of Development of Registries in India in 1997.

She was also deeply concerned about the quality of patient care and developed protocols that went beyond treatment to holistic care. The science of oncology for her gets encompassed in an overarching 'ethic of care'. Many of the patient centric systems for the doctors and the nursing staff which she created four decades earlier are much more stringent than that of National Accreditation Board for Hospitals \& Healthcare Providers (NABH).

Her say had a major impact in many other areas. She played a lead role in making cancer drugs duty exempt, free travel/ travel concession for cancer patients in trains and buses and making cancer a notifiable disease.

She published over 95 papers in national and international journals, contributed chapters in Oncology books, delivered many prestigious orations and participated in many international and national conferences. She was on WHO Advisory Committee on Cancer till March 2005. She was also Convener of the State Advisory Board on Cancer. She was the Chairman of the INDO-US Collaborative Group on Lymphoid Neoplasias (Indian Chapter), member of many ICMR Committees, member of the ICMR Task Force on
Registries and member of the Syndicate of the Anna University. She was the President of the Indian Society of Oncology (88-90), President of the Asian \& Pacific Federation of Organizations for cancer control (97-99). She was a member of the state planning commission on health and expert in the group to dispel apprehensions of the Kudankulam nuclear power project.

\section{Awards and Recognition}

"Our greatest reward is to bring a smile on the face of suffering, cure where possible, relief always. To us, the award is far more than a personal distinction. Its spiritual value and moral strength exceed all else."

The awards are a tribute to Dr. Shanta's pursuit of excellence but equally about outreach to the poor and nurturing of a holistic ethic of service and care. She deservedly received more than 70 awards. She received more than 15 life time achievement awards notable amongst which are those from the TN MGR Medical University and from Lions Club International.

She has been awarded four honorary doctorates (DSc) from Venkateshwara University, TN MGR University, NTR University and Sathyabhama University.

She was awarded the Avvaiyar award by the Government of Tamil Nadu in 2013.

The Government of India has honored her with all the three Padma awards. Padma Sri in 1986, Padma Bhushan in 2006 and the second highest civilian award the Padma Vibhushan in 2016.

Fig. 4 Ramon Magsasay Award - The Asian Nobel (2005). Citation: "In an era when specialised medical care in India has become highly commercialised, Dr. Shanta strives to ensure that the Institute remains true to its ethos, 'Service to all.' Its services are free or subsidised for some 60 per cent of its 100,000 annual patients"

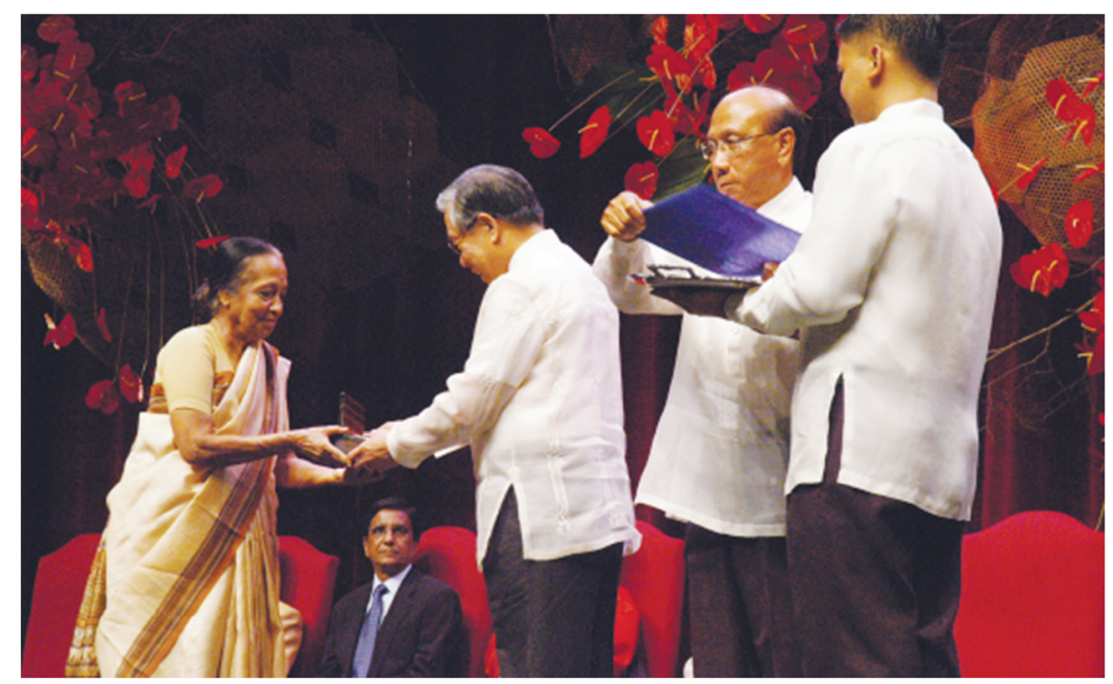


Fig. 5 Padma Vibhushan (2016)

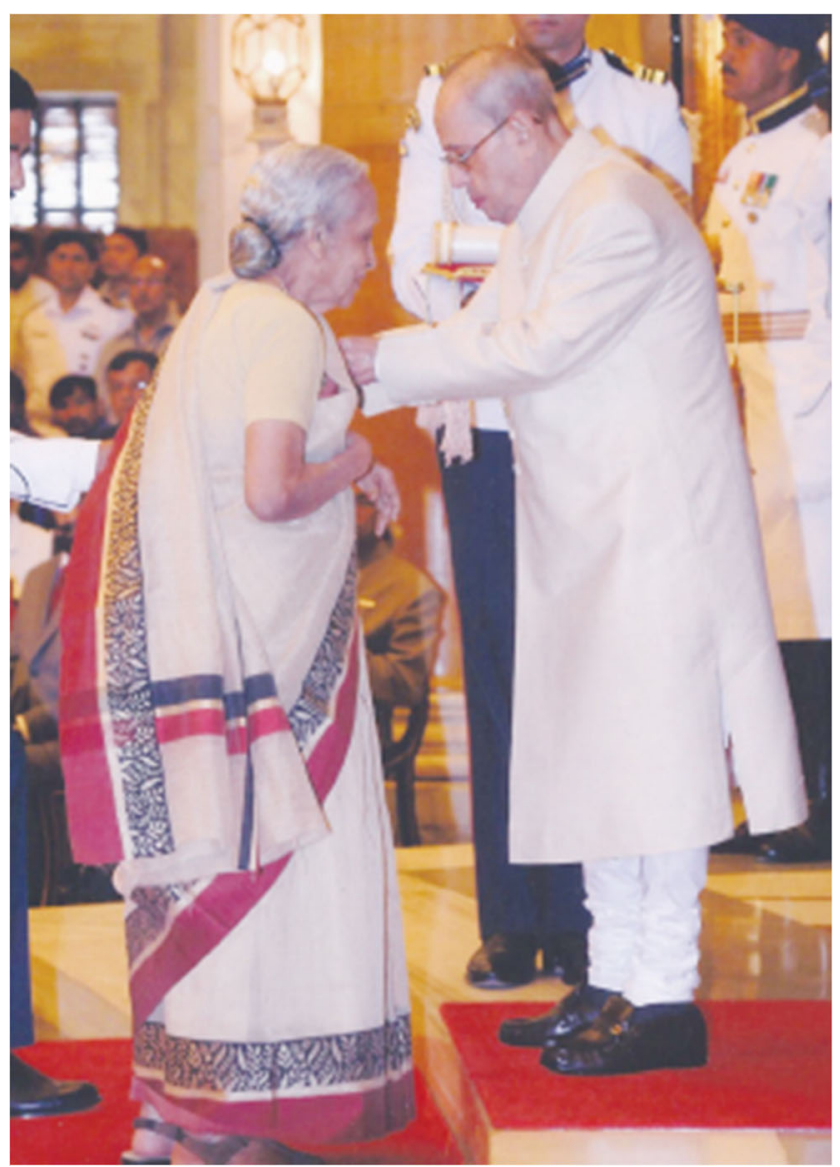

She received the Asian Nobel - the Ramon Magsasay award for public service in 2005. When she shared it with Dr. Krishnamurthy, his immediate reaction was "Wonderful! It will greatly strengthen our cause; it will help us raise more funds". His reaction was typical of the Cancer Institute's ethos from its very inception. They never regarded themselves as individuals, only as members of a mission of service, transcending geography, race and religion. Honors, successes and failures concern them only to the extent that they are likely to affect their mission.

\section{Her Thoughts and Message}

"Treat patients as individual human beings, not as a disease state. And do so with compassion."

Dr. Shanta's favorite mantra was "Fear not cancer diagnosis, but its delay." She was committed to propagating the message that early cancers are curable, from the early 1960 s onwards. She stressed on the fact that cancer treatment needs to be more accessible and affordable. She felt the costs were very high.

The ' $C$ ' word may signify cancer for thousands of patients but it also symbolizes care, cure and compassion for Dr. Shanta. The three elements, excellence, outreach and an ethic of care have come together in the making of the karma yogi Dr. Shanta. Although she stopped operating in 2005, after recovering from a mild stroke, she would still see patients, and was still on call twenty-four hours a day. When she was asked as to what kept her going she remarked "The desire to do more and more. Being involved in cancer control, we realize that what has been done so far is infinitesimal compared to what still needs to be done."

She expressed her outrage when the word 'cancer' is used to refer to anything that is difficult to control like terrorism and corruption. While corruption is a crime and something to be ashamed of, cancer is not. She strongly felt that cancer patients should not be associated with guilt or dread or helplessness and definitely not shame.

When asked about lows she told "Back then, the most painful and frustrating was the divide between the government and non-government organizations. A non-government organization was never accepted as a co-worker or as a partner, but quite often as a competitor. We did face these terms initially 'close the shop' and 'justify the need for a library' - but that only highlighted the ignorance of the people and their mind set at that time. In fact, we have been pioneers in many areas, but most often they have gone unrecognized. Today, however, there is a growing understanding of the services and the Institute itself. There have been people who have recognized our work and helped us, both nationally and internationally, and we are very grateful to them. Through all the difficult times, we never lost sight of our vision of top quality service to all, particularly the economically weaker sections."

When asked as to what still needs to be done she said that "We as a nation need to do a lot more towards early detection and creation of awareness about prevention of cancer. We need to make diagnosis and treatment accessible to larger numbers. A large share of patients still cannot reach a care centre that can provide them treatment, specialty care or even standard care. Palliative care is again something that a very small percentage is entitled to in this country and this needs to change. Lastly, we need to accelerate and continue our research practices to keep up with the latest advances so that our patients get the best care".

Her vision for the younger generation: "The younger generation must ensure that the wonderful technologic advances they have are to be used not because they are available, but because they add value and are cost-effective. They must participate in areas where there is social injustice in healthcare; express their opinion without fear, where corruption exists and where change is needed. Take important decisions for your patients as you would take for your dear ones." 
Fig. 6 Narendra Modi: V Shanta Will be remembered for her outstanding efforts to ensure top-quality cancer care. The Cancer Institute at Adyar, Chennai is at the forefront of serving the poor and downtrodden. I recall my visit to the Institute in 2018. Saddened by Dr. V Shanta's demise. Om Shanti

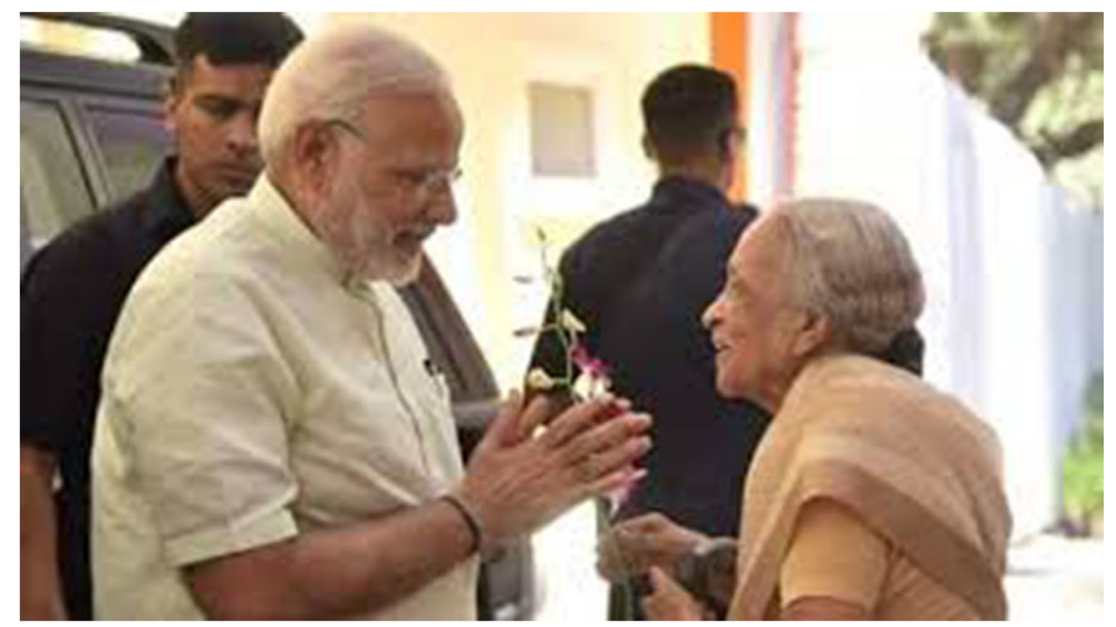

Her unfaltering service to all makes one wonder as to how she sustained the determination to treat everyone who came to her hospital. The answer lies in what she absorbed in her formative years. From her teachers and family she learnt the principle 'to give and not take', 'everything for every patient'. She did not want to deprive anyone of treatment for lack of financial resources, and there was a distinct sense of satisfaction in working for others.

\section{Her Last}

She participated in Tamil Nadu Cancer Registry Project as recent as 28th December 2020 indicating her active involvement till the last. After more than six decades of dedicated selfless service to cancer patients, she breathed her last in the early hours on 19th January 2021. The void she has left cannot be filled. Although the saint is no more with us, but her legacy in words and deeds will remain etched in all of us. Dr. Shanta was a remarkable person and an incredible individual. The meaningful life she led by making an impact on millions of patients and inspiring generations of health-care providers makes her immortal.

Publisher's Note Springer Nature remains neutral with regard to jurisdictional claims in published maps and institutional affiliations. 